\title{
Optimization of Accounting Information System for Enterprises in Smart City by Intelligent Sensor under the Internet of Things
}

\author{
Xiaoguang Li \\ The Tourism College of Changchun University, Changchun 130607, Jilin, China \\ Correspondence should be addressed to Xiaoguang Li; lxg@tccu.edu.cn
}

Received 10 November 2021; Revised 28 December 2021; Accepted 6 January 2022; Published 25 February 2022

Academic Editor: Haibin Lv

Copyright (c) 2022 Xiaoguang Li. This is an open access article distributed under the Creative Commons Attribution License, which permits unrestricted use, distribution, and reproduction in any medium, provided the original work is properly cited.

\begin{abstract}
In order to realize the continuous optimization of the enterprise financial accounting information system of the smart city, from the perspective of intelligent sensor technology, firstly, this paper understands the use feelings of the enterprise financial accounting-related personnel about the information system in the smart city based on the relevant theories of intelligent sensor, smart city, and accounting information. Secondly, the Internet of things technology and intelligent sensing technology are applied to the optimization of enterprise financial accounting information system. Finally, the corresponding opinions and suggestions are put forward from the perspectives of government, employees, and enterprises. The results show that about $40 \% \sim 60 \%$ of enterprise financial accountants believe that data integration and sharing, data governance, and data operation management systems need to be continuously optimized and upgraded. Applying the Internet of things technology and intelligent sensing technology to the optimization of enterprise financial accounting information system, it is found that it can not only improve the accuracy of financial data processing, but also receive the required results efficiently and in real time. It is more important to apply intelligent sensing technology to enterprise financial information system. After comparison, it is found that the net profit of the enterprise increased from 112.69 million yuan to 3329.33 million yuan. The owner's equity of the enterprise increased from 2045.68 million yuan to 11177.34 million yuan. The cash flow of the enterprise increased from 1056.91 million yuan to 6892.56 million yuan. Therefore, this paper studies how to optimize the enterprise financial accounting information system based on the intelligent sensor of the Internet of things in the smart city, which has great reference significance for the management of enterprise financial operation.
\end{abstract}

\section{Introduction}

With the continuous development of information technology, the IoT is changing the lives of smart cities at an alarmingly fast speed, bringing great convenience to people's lives, and promoting enterprises to save production time and facilitate the real-time transmission of information. However, the intelligent sensing technology of the IoT brings opportunities to all aspects of enterprises, but there are also challenges. In this context, the enterprise financial accounting information system is faced with the rapid rise of the IoT. Therefore, improvement and promotion of the original model have become a trend. The accounting information system plays an extremely important role in enterprises. Optimizing the enterprises' accounting information system can identify the enterprises' weak links and provide the theoretical basis for enterprises to improve control efficiency and competitiveness $[1,2]$.

Kazimierz and Metallic believed that intelligent sensor is an important support for the operation of IoT. They used intelligent sensing and IoT to obtain the data of geographic information, made real-time map, and proposed a new concept, which is about the virtual sensor based on abstract objects such as parcel theory [3]. Weber realized the protection of enterprise AIS from the aspect of the confrontation abilities against financial risks and network attack, as well as self-recovery ability after being invaded by viruses and security protection ability of data information, using radio frequency identification (RFID) [4]. From the perspective of data security, Lee introduced the time slot algorithm-Area Locations of Hazardous Atmospheres (ALOHA)-and the improved binary tree search 
algorithm and proposed a computer data encryption method to realize the anti-counterfeiting and protection of enterprise AIS [5]. Tong proposed a new operation method based on the data information encryption, which can optimize and fit the information data while encrypting. Finally, the data presented by the computer are complete and effective [6]. Li discussed how to optimize the enterprise AIS from the perspective of employee salary performance and combined the employees' yearend bonus with the enterprises' benefit and cost, to strive to achieve the goal of development of employees and the enterprise [7]. Sun et al. comprehensively expounded the close relationship between enterprise accounting informatization and corporate governance in smart cities and put forward that the development of enterprise accounting informatization was the premise of corporate governance. Enterprise accounting informatization can help to promote the governance and development of smart cities [8]. Cai et al. analyzed the organizational structure and business processes based on the accounting information system production process theory and internal control theory. The results achieved through the analysis and design of the accounting information system production process are desktop-based applications that can assist in the activities of the production process, particularly in the recording and storage of transaction data and preparing reports as required by the enterprises [9]. Akyol et al. pointed out that the development of intelligent sensing technology of the IoT could enable enterprises to grasp the information of goods in circulation anytime and anywhere, grasp and manage the details of the circulation of goods in a timely manner, realize the informatization of the circulation process of goods, strengthen the supply management of goods in enterprises, and save the operation cost of enterprises. However, in practical applications, it is found that more contents need to be considered, such as the safety and timeliness of goods information [10]. Compared with the theories and methods proposed by the above experts and scholars, a questionnaire survey is used to analyze the use of information systems by corporate financial accountants from a global perspective, which is logical and reliable.

In summary, IoT technology and intelligent sensing technology are used to investigate the relevant personnel of enterprise financial accounting in the smart city, to study and analyze the data integration and sharing, data governance, and data operation management of the information system. Then, intelligent sensing technology is introduced into the financial information system to observe whether it can have a positive effect on the optimization of the system. Finally, effective opinions and suggestions are put forward, aiming at providing a methodological reference for the continuous optimization of the enterprise financial accounting information system in the smart city. To illustrate the writing logic more clearly, Figure 1 depicts the specific organizational structure.

\section{Construction of the Intelligent Sensing Model}

The basic concept of a sensor system is a system that senses information through sensing elements, converts them into electrical signals or other forms of signal output according to

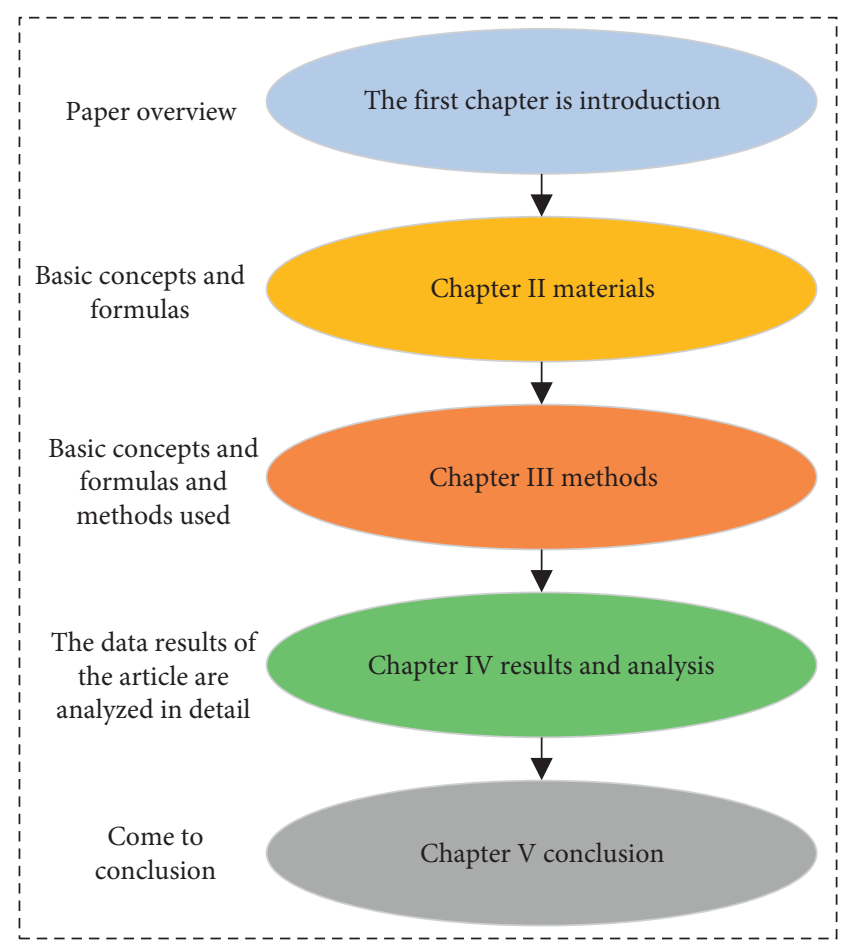

Figure 1: Organization structure.

certain laws, and completes a certain degree of processing and transmission function [11-13]. An intelligent sensor is a sensor with an information processing function. Intelligent sensor with a microprocessor has the ability to collect, process, and exchange information. It is the product of the combination of sensor integration and microprocessor [14]. Compared with general sensors, intelligent sensors have the following advantages: (1) they have the functions of selfzero-calibration, self-calibration, and self-correction; (2) they have automatic compensation function; (3) they can automatically collect data and preprocess the data; (4) they can automatically inspect and select the measuring range and find faults by themselves; (5) they have the functions of data storage, memory, and information processing; (6) they can realize two-way communication, standardized digital output, and symbol output; and (7) they can make judgment and process decisions [15-17].

The intelligent sensors can store various detected data and process them according to the instructions to create new data [18]. Intelligent sensors can exchange information, determine the data to be transmitted, discard abnormal data, and complete analysis and statistical calculation [19]. Figure 2 illustrates the specific structure of the intelligent sensor.

Smart city refers to the integration of various operation systems and service channels of city by using the current advanced information technology and relevant innovative concepts, to improve the living standards of residents and the utilization efficiency of social resources [20]. Smart city is an indispensable and important part of China's social development process. In the process of constructing the smart city, the most advanced IoT technology needs to be adopted, which means every entity in the construction should be effectively connected 


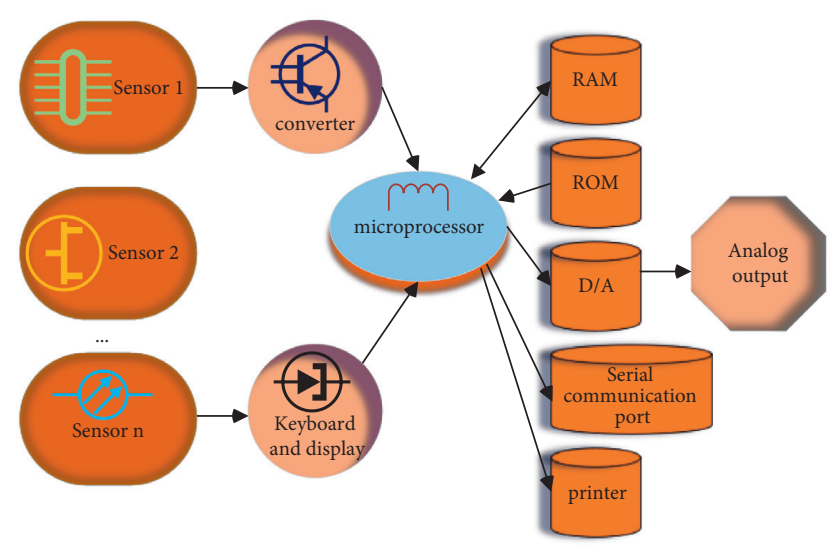

FIgURE 2: Structure of the intelligent sensor.

by the IoT. Cloud computing is taken as the core computing device, and the big data technology is applied to combine modern scientific and technological methods with traditional processes to realize high-end new urban construction [21, 22]. Different from the traditional city construction, the smart city itself has high informatization and intelligence, which can meet the current development needs of China's daily work and greatly promote the long-term development of Chinese society $[23,24]$. However, at present, the construction quality of smart city in China is not satisfactory, which is caused by the lack of effective supervision mode in the construction process. With the introduction of relevant laws in China, people are paying more attention to the management of smart city. Applying modern information technology to the data management of smart city can improve the quality of the data of the whole city to a certain extent, so as to build a modern new city with demonstration nature $[25,26]$.

Accounting information refers to the most important economic information of enterprises and institutions. It continuously, systematically, and comprehensively reflects and supervises the business status of enterprises and provides an important basis for management and business decision making. Accounting information system refers to a system that takes computer as the main tool to collect, store, and process various accounting data, complete accounting tasks, and provide accounting management, analysis, and decision making related accounting information. Its essence is a system that converts accounting data into accounting information, which is a vital subsystem of the enterprise management information system [27]. The functions of the information system are collecting, storing, processing, transmitting, and outputting accounting data. Figure 3 demonstrates AIS.

\section{Key Methods and Algorithms Used in the Research}

Literature research: due to the writing needs, firstly, China National Knowledge Infrastructure, Google Scholar, and other websites are used to query data. Secondly, there are many articles and works from columnists and relevant websites. In addition, many related journal and books are consulted in the school library, such as City of Tomorrow:
Sensors, Networks, Hackers and Future Urban Life and Analysis and Application of Financial Statements. Through the collection and summary of this series of data, literature research provides a favorable theoretical basis for the research ideas and methods [28, 29]. Comparative analysis: comparative analysis method refers to the multiparty comparison of two or more research objects to explore the similarities and differences between them. Good methods obtained through comparative analysis can prove reference to AIS optimization for smart city enterprises based on intelligent sensor under the IoT [30-32]. Questionnaire survey: the enterprise AIS is an important part of each company. The normal operation of the accounting system is related to the stable and long-term operation of the enterprise. However, at present, there are system crises in the enterprise, so the current operation status of the enterprise AIS can be obtained by releasing corresponding questionnaire questions [33-35]. Therefore, 310 questionnaires were randomly distributed to the accounting related personnel of enterprises in model smart cities between June 2019 and August 2020. To make the questionnaire scientific, experts of relevant disciplines are consulted about the questionnaire before it was distributed, and the unreasonable places in the questionnaire are modified. To ensure the corresponding recovery rate, the questionnaire is distributed face-to-face and recovered on the spot. 270 copies were recovered, with a recovery rate of about $87.1 \%, 248$ copies were effectively recovered, and the effective recovery rate was $91.85 \%$. Figure 4 presents the specific steps of the questionnaire survey.

To make the results of the questionnaire more accurate, the validity test of systematic error variance is introduced as shown in the following equation:

$$
r=\frac{\sum X Y-\sum X \sum Y / N}{\sqrt{\sum X^{2}-\left(\sum X\right)^{2} / N \sqrt{\sum Y^{2}-\left(\sum Y\right)^{2} / N}}}
$$

where parameter $r$ denotes the reliability, $X$ represents the dependent variable, $Y$ refers to the independent variable, and $N$ indicates the quantity.

The score difference of the actual number can be solved out according to equation (2), based on equation (1).

$$
\alpha=\frac{K}{K-1}\left(1-\frac{\sum_{i=1}^{K} \sigma_{Y i}^{2}}{\sigma_{X}^{2}}\right),
$$

where $\alpha$ denotes the correlation coefficient, $K$ represents the number of samples, and the other letters in equation (2) have the same meaning as above. In general, the higher the reliability coefficient, the higher the reliability between variables, indicating higher internal consistency between variables. Parameter $\alpha$ being less than or equal to 0.3 indicates that the variable is not credible; parameter $\alpha$ being between 0.3 and 0.4 indicates that the variable is initially credible; parameter $\alpha$ being between 0.4 and 0.5 indicates that there is a slight credibility between variables; parameter $\alpha$ being between 0.5 and 0.7 indicates that the variables are credible; parameter $\alpha$ being between 0.7 and 0.9 indicates that the variables are greatly credible; parameter $\alpha$ being greater than 0.9 indicates that the variable is totally credible. 


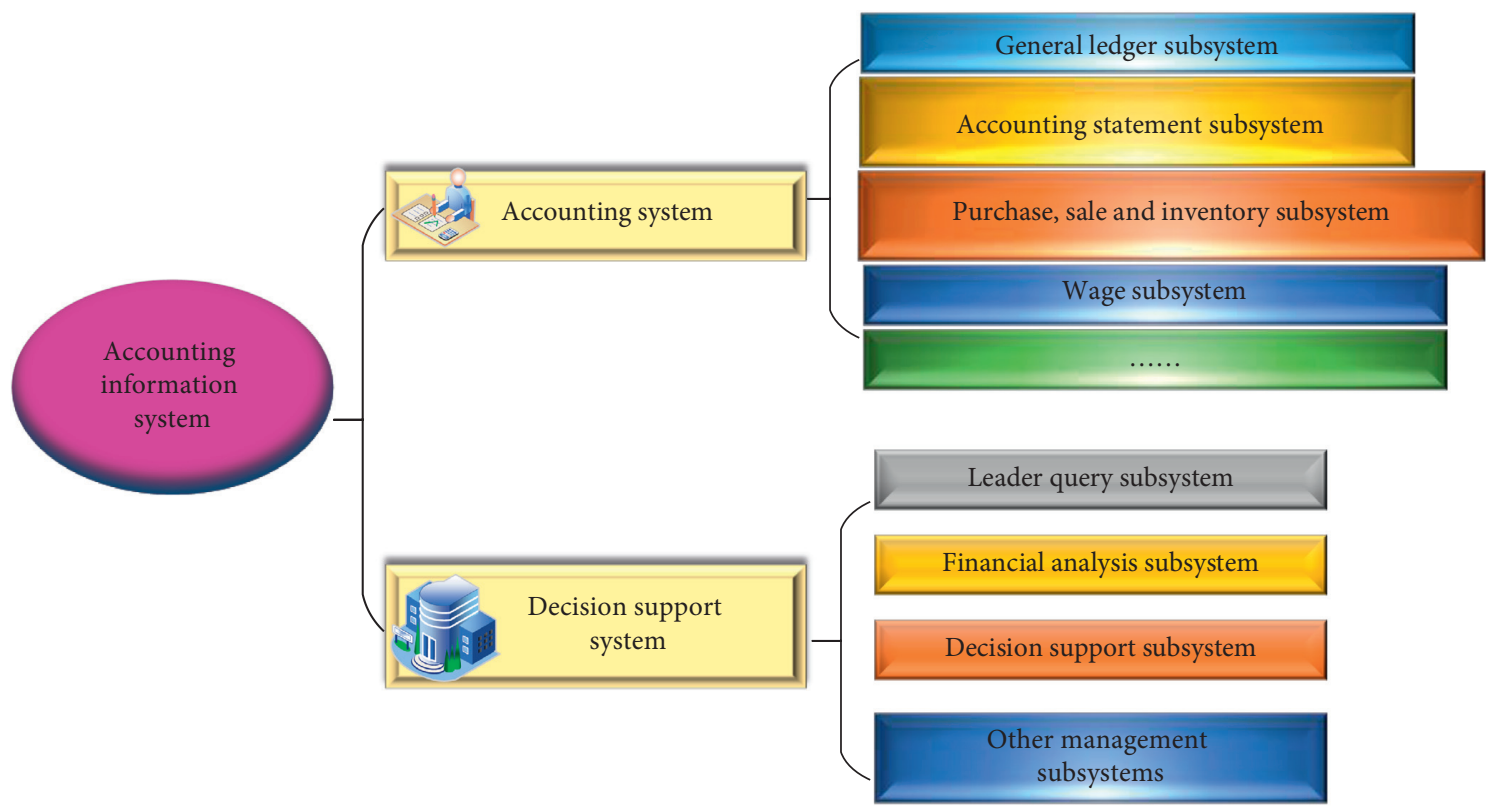

FIgURE 3: AIS.

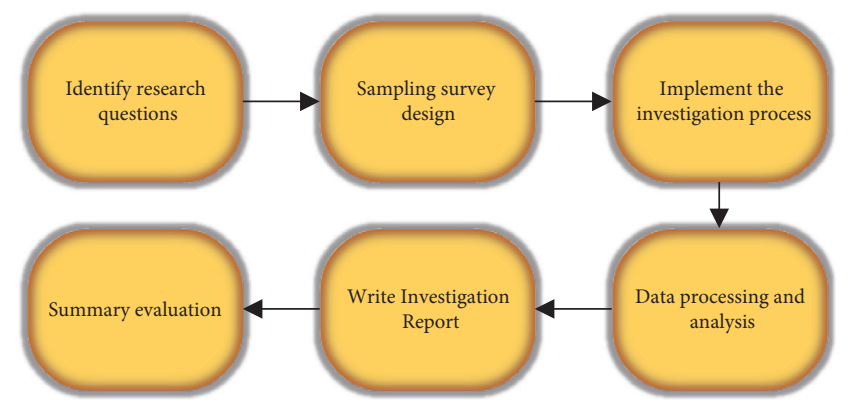

FIgURE 4: Steps of the questionnaire survey.

Through the reliability test of internal consistency of the answers to the questionnaire through equation (2), the result is 0.86 , indicating that the reliability of the questionnaire is high.

Equation (3) can express the logic topology optimization problem of intelligent sensor.

$$
\min S(x)=\sum_{\gamma}\left[\sum_{l \in L} t\left(l_{j}\right)+\sum_{n \in N} t\left(n_{i}\right)\right],
$$

where $S(x)$ represents the total delay of the system, $t\left(l_{j}\right)$ denotes the delay on the link $\left(l_{j}\right), t\left(n_{i}\right)$ refers to the delay of the node $n_{i}, \gamma$ accords to the set of all data transmission paths, $L$ indicates the total link, and $N$ stands for the total node. Equation (4) demonstrates the calculation method of link reliability.

$$
E\left(l_{j}\right)=G\left[a\left(l_{j}\right)\right]
$$

where $E\left(l_{j}\right)$ represents the reliability of the $\operatorname{link} l_{j}, G$ refers to the functional relationship between link reliability and link unit price, and $a$ denotes the cost. Equation (5) illustrates the specific calculation method of node reliability.

$$
E\left(m_{j}\right)=F\left[a\left(m_{j}\right)\right]
$$

where $E\left(m_{j}\right)$ represents the reliability of node $m_{j}, F$ accords to the functional relationship between node reliability and node cost, and $a$ stands for the cost. Figure 5 displays the specific structure of nodes in the intelligent sensor.

Equation (6) shows the calculation method of waiting transmission time in the intelligent sensor.

$$
T(n)=t_{m^{\prime}} t_{m}=t_{m^{\prime}}-t_{n}+t_{n}-t_{m}
$$

where $T$ represents the time, $n$ stands for the number, $m$ refers to the group, and $m^{\prime}$ indicates the corresponding group of the group. Based on equation (6), equation (7) signifies the calculation method of obtaining the average waiting time of the intelligent sensor.

$$
\bar{T}(n)=\frac{(n-1)(\gamma+\alpha \beta)+n \alpha\left(\beta^{2}-\beta\right)}{2(1-n \alpha \beta)},
$$

where $T$ represents the time, $n$ refers to the number, $\alpha$ indicates the information arrival rate, $\beta$ accords to the service rate of the classified service information, and $\gamma$ denotes the coefficient.

Equation (8) illustrates the calculation method of time required for grouping two information groups of intelligent sensors.

$$
T_{a, b}=\sum_{i=1}^{n}\left(L_{a, b}+T_{a, b}\right),
$$

where $T$ represents the time and $n$ refers to the number. When the terminal $a$ receives the service, $b$ denotes the average number of information packets stored in the terminal memory.

Equation (9) demonstrates the calculation method of average queue length of intelligent information system in enterprise AIS. 


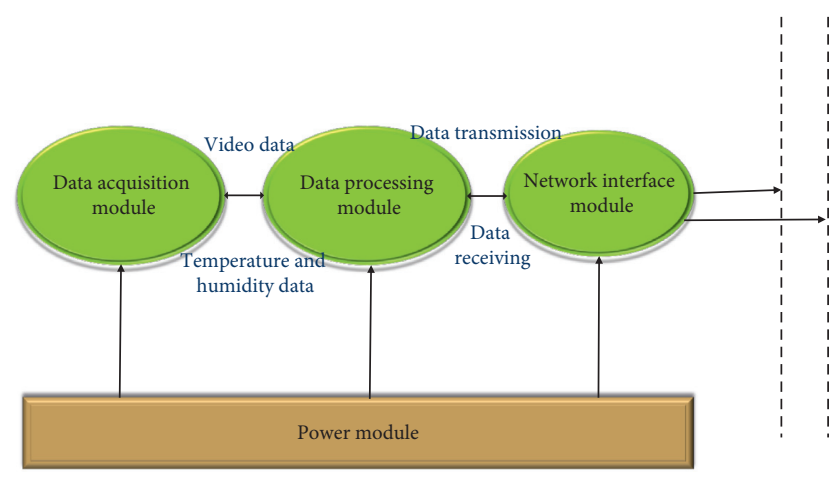

FIGURE 5: Structure of nodes in the intelligent sensor.

$$
\mathfrak{I}=\frac{\gamma(1-\alpha \beta)}{1-\alpha \beta},
$$

where $\mathfrak{I}$ represents the queue length, $\alpha$ means the information arrival rate, $\beta$ indicates the service rate of the service information packet, and $\gamma$ refers to the coefficient.

When the data information is consistent with the verification, the intelligent sensor will feed back the data to AIS. Equation (10) signifies the calculation method of feedback time.

$$
T(a)=\frac{\alpha \gamma(i-j)}{T(a+1)},
$$

where $T$ represents the time, $\alpha$ stands for the information arrival rate, $\gamma$ refers to the coefficient, $i$ and $j$ accord to the transmission time and reception time, respectively, and $a$ represents the corresponding time of a transmission.

\section{Results and Analyses of the Application of Intelligent Sensors}

4.1. Analyses of the Development of Enterprise AIS under Smart City. According to the data obtained from the above questionnaire, Table 1 lists the personal information of the investigated enterprise.

It can be seen from Table 1 that the education of enterprise finance-related personnel is mainly undergraduate, accounting for about $54.6 \%$ of the total education, followed by master, accounting for about $23.7 \%$, followed by college, accounting for about $19.6 \%$ of the total education, and finally doctor, accounting for about $2.1 \%$; as for the "title grade," most respondents are under a "primary" title, accounting for about $46 \%$, followed by "intermediate," accounting for about $34 \%$, and "senior," accounting for about $15.5 \%$. As for the "working years," most respondents have worked for 3-5 years, accounting for about $42.3 \%$ of the total, followed by 5-10 years, accounting for about $26.8 \%, 1-3$ years, accounting for about $17.5 \%, 10-15$ years, accounting for about $9.3 \%$, and finally more than 15 years, accounting for $4 \%$. Hence, under the concept of smart city, the financial accounting of enterprises is still mainly composed of young people with bachelor's degree, who have worked for few years and are under a primary professional title.
TABle 1: Personal information of the respondents.

\begin{tabular}{lcc}
\hline Type & Project & Project (\%) \\
\hline \multirow{4}{*}{ Educational background } & Junior college & 19.6 \\
& Undergraduate & 54.6 \\
& Master & 23.7 \\
& Doctor & 2.1 \\
\hline \multirow{4}{*}{ Title grade } & Primary & 46 \\
& Intermediate & 34 \\
& Senior & 15.5 \\
& Other & 4.5 \\
\hline \multirow{3}{*}{ Working years } & $1-3$ & 17.5 \\
& $3-5$ & 42.3 \\
& $5-10$ & 26.8 \\
& $10-15$ & 9.3 \\
& More than 15 years & 4.1
\end{tabular}

Accountants of enterprise are the initial users of the financial system, and their user experience is the most authentic and reliable. In the next, investigation is carried out on their evaluation on the current enterprise AIS. Figure 6 displays the specific results.

Figure 6 demonstrates that the evaluation of information system is mainly carried out from three aspects, namely: data collection, data integration, and data sharing. In terms of data collection, $59.82 \%$ of financial personnel thought it needed to be improved, $26.8 \%$ of financial personnel thought the user experience was general, 9.28\% thought the experience was very adverse, $3.1 \%$ of financial personnel thought the user experience effect was good, and only $1 \%$ thought the user experience effect was great. In terms of data integration, $42.27 \%$ of the financial staff thought it needed to be improved, $37.15 \%$ of the financial staff thought it was average, $17.53 \%$ thought it was adverse, $2.06 \%$ of the financial staff thought it was good, and only $1 \%$ of the financial staff thought it was good. In terms of data sharing, $45.36 \%$ of the financial personnel thought it needed to be improved, $35.08 \%$ of the financial personnel thought the experience was average, $18.56 \%$ thought the experience was poor, and $1 \%$ thought the experience effect was good. This shows that whether it is from data integration, data collection, or data sharing, the information system needs to be improved continuously. Moreover, many respondents thought the user experience is adverse for data sharing, so it is of great importance to optimize and improve the enterprise AIS.

Meanwhile, investigation is implemented on the problems of data governance in AIS of enterprises under smart city. Figure 7 demonstrates the specific evaluation results.

As Figure 7 signifies, in terms of data management, $46.42 \%$ of financial personnel in enterprise think it needs to be improved; $28.87 \%$ of financial personnel in enterprise think it has an adverse user experience; $23.71 \%$ of financial personnel in enterprise think the user experience is general, and $1 \%$ of financial personnel in enterprise think the user experience is good. As for the metadata management, $52.58 \%$ of respondents think it needs to be improved, $8.25 \%$ of respondents think they have an adverse user experience, $36.08 \%$ of the respondents think the user experience is normal, and $3.1 \%$ of the respondents think the experience is good. In terms of data standard, $24.63 \%$ of the respondents 


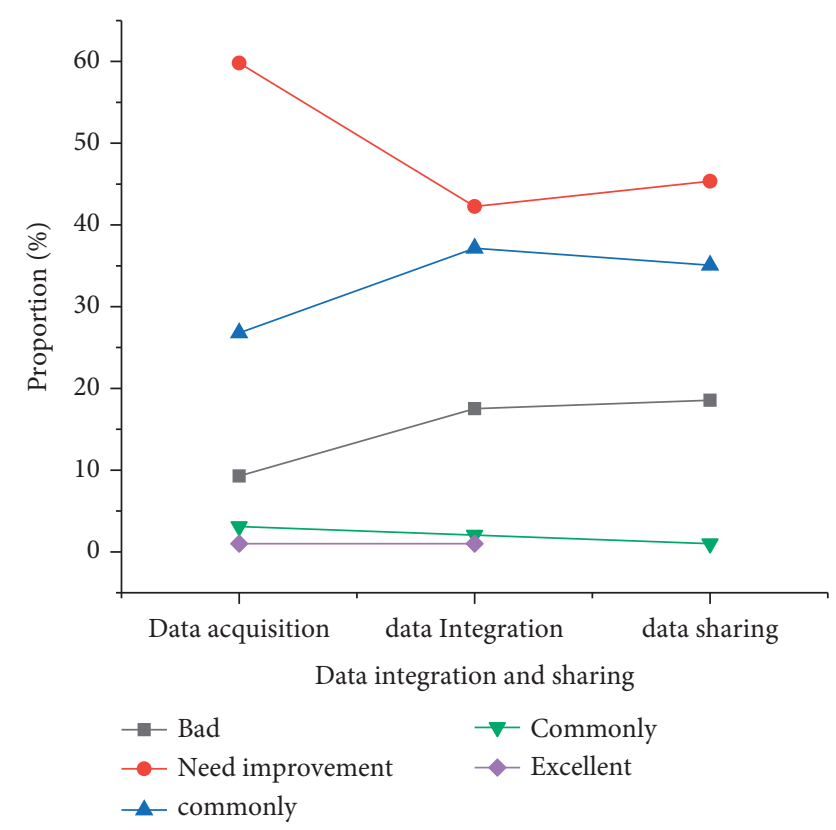

Figure 6: Evaluation of accountants of enterprise on integration and sharing of data in the information system.

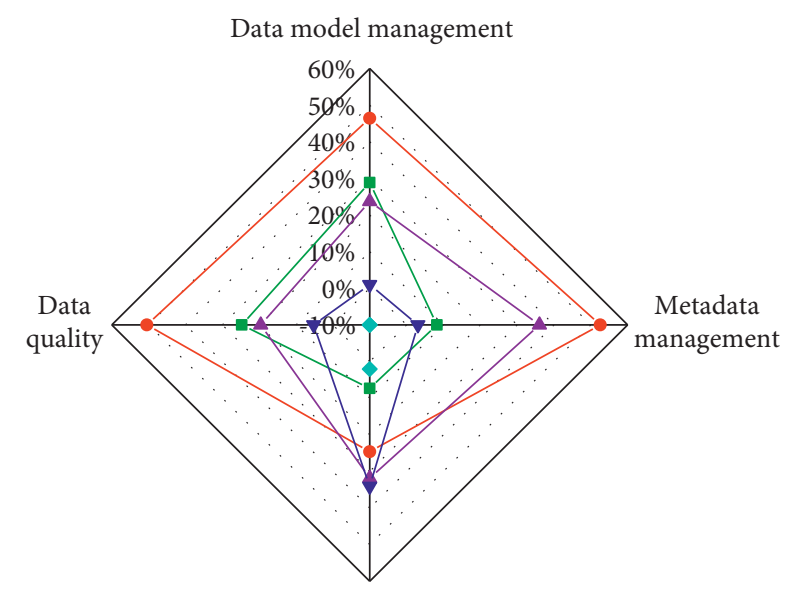

Data standard

$$
\begin{aligned}
& \rightarrow \text { Bad } \\
& \rightarrow \text { Need improvement } \\
& - \text { Commonly } \\
& \rightarrow-\text { Good } \\
& \longrightarrow \text { - Excellent }
\end{aligned}
$$

FIGURE 7: Evaluation of the data governance of the information system from accountants in enterprise.

think it needs to be improved, $7.34 \%$ of the respondents think the experience is very poor, $31.87 \%$ of the respondents think the experience is average, $34.1 \%$ of the respondents think the experience is good, and $2.06 \%$ of the respondents think it is very excellent. In terms of data quality, $50.47 \%$ of respondents think it needs to be improved, Among them, about $24.74 \%$ of the respondents thought that they felt bad after experiencing the system, $19.59 \%$ of respondents think it is general, and $5.2 \%$ of respondents think it is good. This indicates that data model management, metadata management, data standard, and data quality need to be continuously improved in data governance, and the data management should be strengthened, according to the results of questionnaire, which has the worst user experience.

Additionally, the data operation management was investigated, and Figure 8 signifies the specific results of evaluation.

Figure 8 indicates that in terms of data lifecycle, $44.62 \%$ of respondents think it needs to be improved, $6.19 \%$ of respondents think they have an adverse user experience, $39.9 \%$ of respondents think it is general, and $9.3 \%$ of respondents think it is good. In terms of data security management, $36.42 \%$ of respondents think it needs to be improved, $9.28 \%$ of respondents think it is extremely adverse, $34.2 \%$ of the respondents think their user experience is normal, and $16.2 \%$ of the respondents think their user experience is good. In terms of master data management, $46.39 \%$ of the respondents think it needs to be improved, $43.36 \%$ of the respondents think their user experience is very adverse, $8.25 \%$ of the respondents think their user experience is ordinary, and $2.06 \%$ of the respondents think it is good. This indicates that in the data operation and management, data lifecycle, data security management, and metadata management all need continuous improvement. Also, the research and development of metadata management should be strengthened, whose user experience is the worst.

In conclusion, from the evaluation of data sharing, data governance, and data operation management of enterprise financial AIS, each module needs to be continuously strengthened in the aspects of quality evaluation and optimization. From the perspective of the user experience of financial personnel in enterprise, there are still lots of efforts to be made to build an operation system truly suitable for accounting information management in smart city. Overall, the optimization in this aspect is not enough.

4.2. Application of Intelligent Sensor in Optimization of AIS. With the continuous improvement of modern economy, the enterprise AIS has gradually changed. The traditional model has been difficult to meet the current needs. The application of intelligent induction technology to the optimization of accounting system is the trend of the development of the time. Figure 9 illustrates the specific application process.

As Figure 9 indicates, initially, the intelligent sensors are applied to the enterprise's supply chain management. When each product passes through the intelligent sensor, the system can make timely judgment according to the product attribute, specification, quantity, and size and then transmit the collected effective information to the enterprise's database through the IoT immediately. After verification, if there is any problem in the product, an alarm will be sent out, which will be handled manually. Otherwise, the products will be transported to the corresponding area according to the received information, and then valid vouchers will be automatically generated. Figure 10 indicates the specific process of collection and transportation of accounting information. 


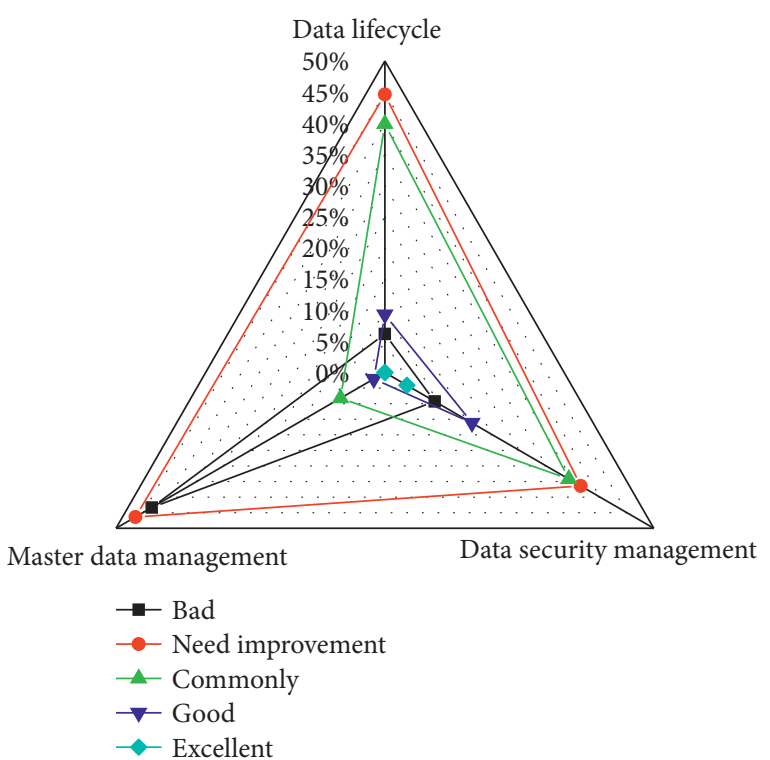

Figure 8: Evaluation on the data operation management of the information system from accountants in enterprise.

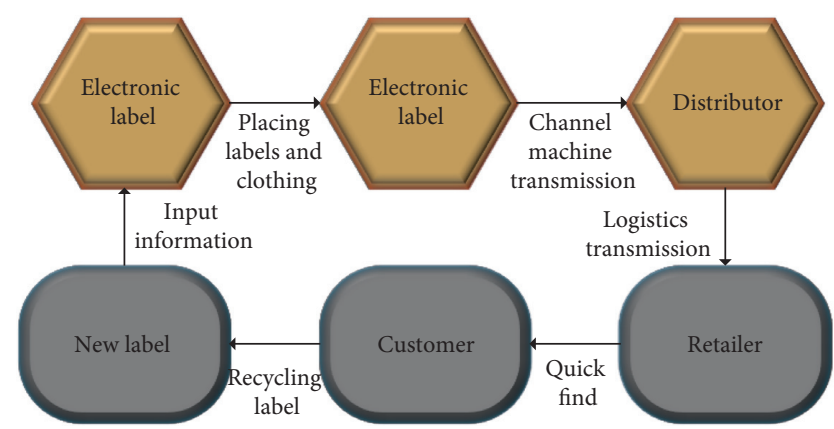

FIGURE 9: Application of intelligent sensors in the supply chain system of enterprise.

As Figure 10 signifies, when the information of each product identified through the intelligent sensor is consistent with the system, the intelligent sensor system will issue a command to open the "commodity channel"-the entrance allows the commodity to be delivered to the corresponding area. Simultaneously, when the information is consistent, the intelligent sensor will also make the information transmitted to the enterprise AIS through the IoT, to timely and effectively complete the information collection, statistics, and feedback of the accounting information. Application of the intelligent sensors can both avoid the problem of human participation in data errors and ensure the prompt data upload.

Intelligent sensors based on the Internet of Things can have a beneficial impact on the production, transportation, and manufacturing of enterprises; moreover, it can realize the effective management of accounting information. Figure 11 demonstrates the specific architecture of AIS.

Figure 11 implies that AIS is composed of accounts, procurement, cost, and other subsystems. The intelligent sensors based on the Internet of Things are applied to AIS, which can output account certificates, statements, and

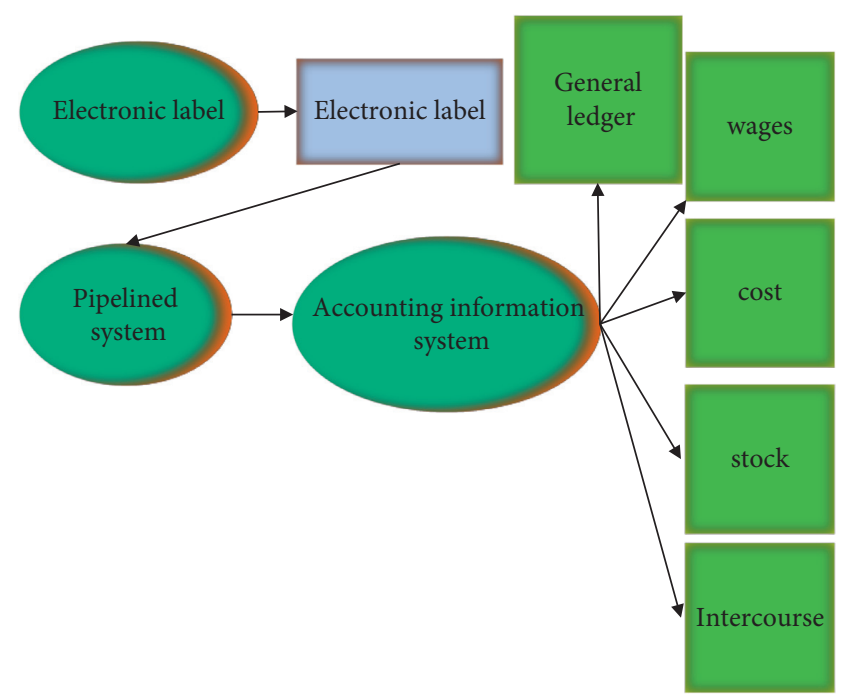

Figure 10: Process of the collection of accounting information.

special information promptly and efficiently and realize the analysis of aging and other information.

After the application of intelligent sensing technology to the enterprise's supply chain management, the enterprise's management level in various links such as goods purchase, storage, transportation, and sales has been improved to a certain extent. The corresponding enterprise financial AIS has greatly improved the data sharing, data governance, and data operation efficiency. It has an impact on the enterprise financial accounting data of the smart city, which is the most obvious, as shown in Figure 12.

Figure 12 suggests that in the past five years, the net profit of the enterprise has increased from 112.69 million yuan to 3329.33 million yuan. The owner's equity increased from 2045.68 million yuan to 11177.34 million yuan; the cash flow of the enterprise increased from 1056.91 million yuan to 6892.56 million yuan. Based on the above data, it can be found that the introduction of intelligent sensing technology into enterprise financial accounting management has significantly improved assets, profits, and owner's equity. It can be seen that intelligent sensing technology can improve the core competitiveness of enterprises.

4.3. Suggestions on Optimization of Enterprise AIS by Intelligent Sensors. Compared with ordinary cities, smart cities have more stringent requirements and higher positioning for enterprise AIS. Enterprise AIS should not only maximize the interests of the company but also focus on analysis and decision making. To realize the optimization of AIS, it should be improved from many angles and aspects. The specific suggestions are as follows. (1) Hui and Wei pointed out in their published papers that the intelligent sensing technology of the IoT had three main risks in cost, security, and privacy. Only by solving the problems of cost, security, and privacy, can the Internet of things technology be better applied in the enterprise financial accounting information system. [36]. Hence, as for government, it should strengthen guidance and supervision, establish special organizations to control AIS in the smart city, seriously deal with any illegal 


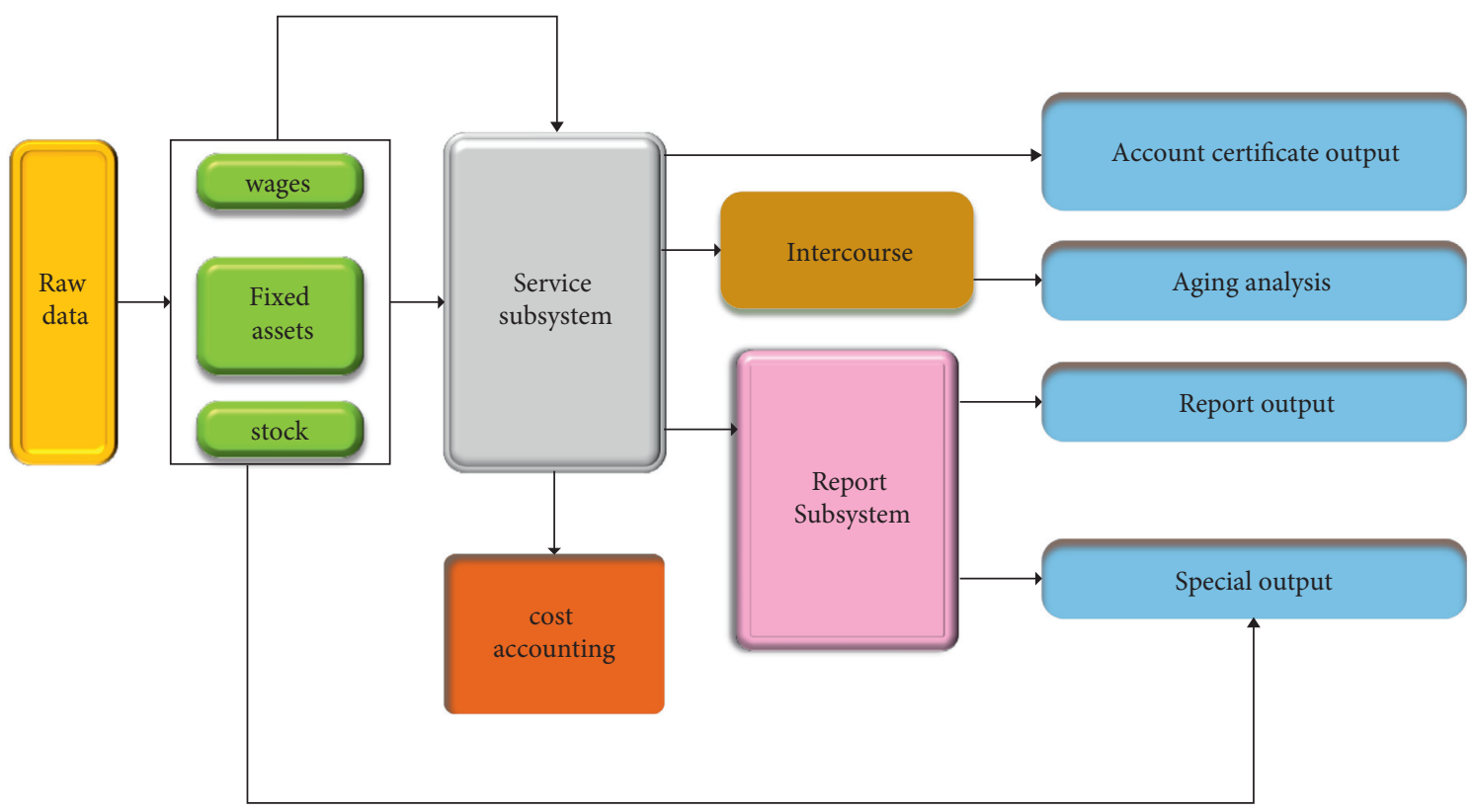

FIgURE 11: Architecture of AIS.

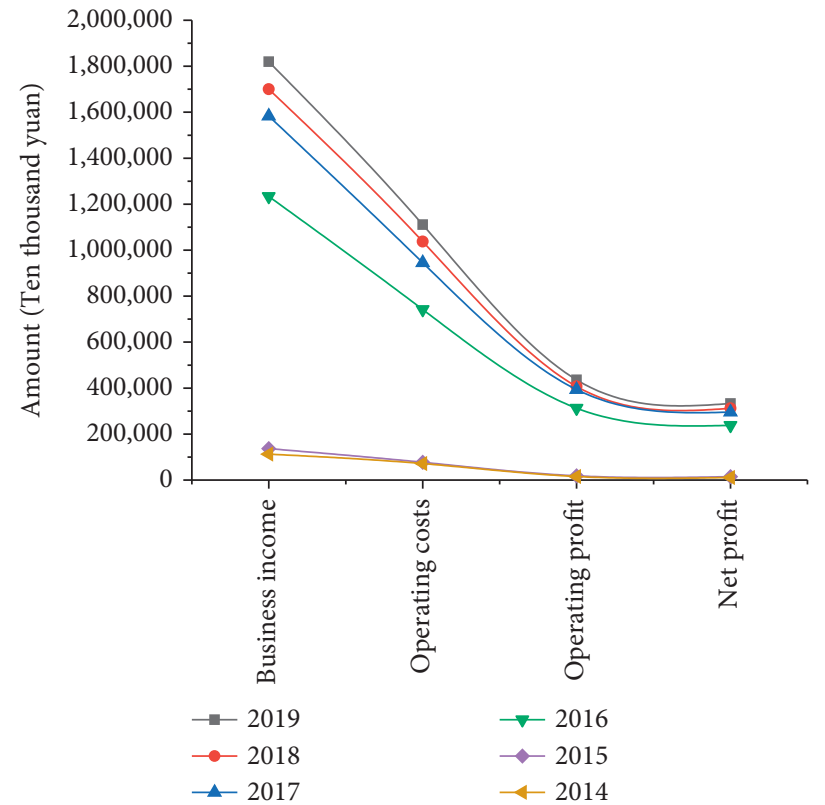

(a)

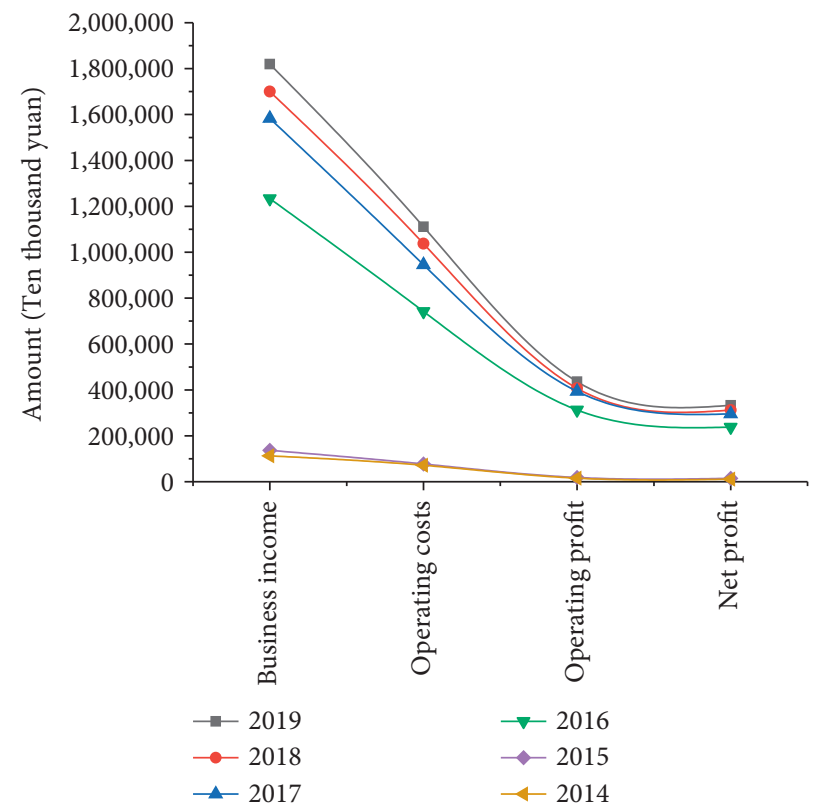

(b)

Figure 12: Continued. 


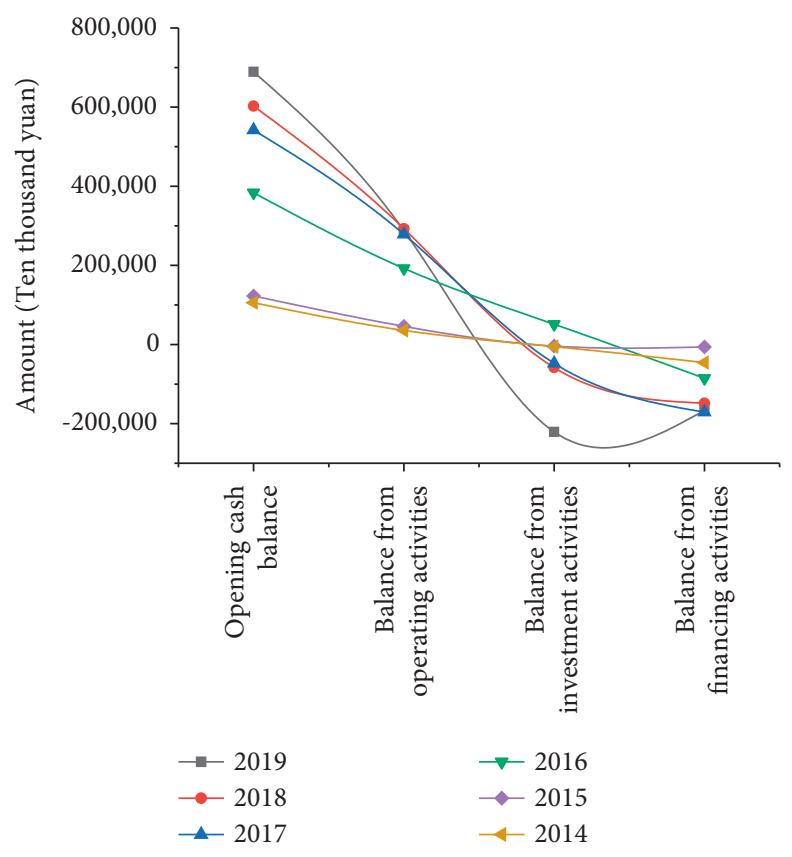

(c)

FIGURE 12: Impacts of intelligent sensors on the enterprise accounting data: (a) balance sheet; (b) profit statement; (c) cash flow statement.

enterprises, and return the society with a harmonious and honest atmosphere. Additionally, the government should also call on high-quality talents to devote into the optimization of AIS. Government should also increase the financial support for the R\&D of information system, to promote the rapid development of AIS. (2) Zhao and Qiu analyzed the impact of accounting informatization under the background of big data era and put forward the problems of the security of accounting information and the lack of accounting data standards [37]. As for enterprise, it should always strengthen the cultivation of enterprise employees' awareness of information security to avoid the invasion of Trojan horse and other computer virus and the stealing of important information and strengthen the management on the authority and times of database access whenever a large amount of information is transmitted to the enterprise. Meanwhile, enterprise should strengthen information exchanges and cooperation with other companies and enterprises in the market and learn from other enterprises to obtain practical experience. Based on actual situation, the beneficial methods and experience should be drawn to improve the AIS optimization of enterprise. Moreover, enterprises should follow the trend of the development of the time, apply intelligent sensing technology and IoT to the operation of AIS, and improve the security of employee system and the effectiveness of AIS. (3) As for enterprise accountants, they should strengthen professional ethics, improve their own binding force, always take integrity as the first criterion, and stick to their principle in the face of illegal temptation in the society. Simultaneously, the enterprise should also establish a reward and punishment system to link the business integrity processing level of the enterprise's financial accounting personnel with the salary, resolutely dismiss the illegal employees, and give corresponding rewards to the employees with excellent performance and those who can correctly handle financial information. (4) Under the rapid development of the information, most of the work of accounting has been done by computers with high accuracy and efficiency. Only by constantly enriching their professional knowledge and practical ability, accountants will not be eliminated by the time. They should constantly improve their own requirements, strive to become compound talents, and improve their own value.

\section{Conclusion}

With the continuous development and improvement of the level of science and technology, the application scope of the IoT intelligent sensing technology is also expanding, from the initial logistics industry to agriculture, construction, and other industries, and now it can still be involved in the enterprise financial accounting information system. Through the application of IoTand intelligent sensors in the enterprise AIS in smart city, the following conclusions can be drawn. (1) After conducting a questionnaire to the accountants of enterprise in smart city, it is found that they do not have a good user experience in the aspects of information system data integration and sharing, data governance, and data operation and management. Data sharing in data integration and sharing receives the worst comments; the evaluation of data quality in data governance performs the worst; the evaluation of metadata management in data operation management refers to the worst. In short, each module needs to continuously strengthen quality evaluation and optimization. (2) The application of IoT technology and intelligent sensors in enterprise AIS can both improve the operation efficiency and reduce the mistakes caused 
by human operation. (3) After applying the intelligent sensor technology to the enterprise AIS, it can be seen from the financial data of the previous five years that the enterprise's assets, profits, and owner's equity have been significantly improved, and the enterprise's net profit has increased from 112.69 million yuan to 3329.33 million yuan. The owner's equity of the enterprise increased from 2045.68 million yuan to 11177.34 million yuan. The cash flow of the enterprise increased from 1056.91 million yuan to 6892.56 million yuan. (4) Finally, aiming at the existing problems of AIS, corresponding opinions and suggestions are given from the perspectives of government, employees, and enterprises to simultaneously promote the optimization of enterprise AIS.

Due to limited energy, there are certain limitations in data acquisition, resulting in some deviations in the analysis of relevant data. Additionally, intelligent sensing technology has not been discussed in economic investment in the optimization of financial accounting information system of enterprises in smart cities. Subsequently, benefit evaluation can be carried out according to the specific situation, so that this technology can bring certain influence to the relevant management departments, enterprises, or employees.

\section{Data Availability}

The data used to support the findings of this study are included within the article.

\section{Conflicts of Interest}

The author declares that there are no conflicts of interest.

\section{Acknowledgments}

This achievement was financially supported by the Agriculture and Rural Department Fund Project of Jilin Province: Research on Development Path of Rural Financial Informatization in Jilin Province (project no. JNDY2021047) and Fund Project: Gold Course Construction Project of Financial Management in the Tourism College of Changchun University in 2021.

\section{References}

[1] Y. Wang, W. Zhou, and J. Luo, "Reliable intelligent path following control for a robotic airship against sensor faults," IEEE/ASME Transactions on Mechatronics, vol. 12, no. 99, p. 1, 2019.

[2] A. Smke, B. Ga, and C. Tcm, "Use of smart intelligent sensor \& actuator mechanical materials (PVDF/PZT) in developing MIMO mathematical model of the smart structure and its use to control the active vibrations using discrete sliding mode control theory with output samples," Materials Today: Proceedings, vol. 45, no. 78, pp. 41-43, 2021.

[3] H. Kazimierz and B. Metallic, "Sandwiched-aerogel hybrids enabling flexible and stretchable intelligent sensor," Nano Letters, vol. 20, no. 5, pp. 3449-3458, 2018.

[4] L. Weber, "The application research of new-type patrol robot based on intelligent sensor," Henan Science and Technology, vol. 11, no. 48, pp. 52-55, 2018.
[5] M. Lee, "Building a compact convolutional neural network for embedded intelligent sensor systems using group sparsity and knowledge distillation," Sensors, vol. 19, no. 19, pp. 437-440, 2019.

[6] L. Tong, "Intelligent sensor-cloud in fog computer: a novel hierarchical data job scheduling strategy," Sensors (Basel, Switzerland), vol. 19, no. 23, pp. 11-15, 2019.

[7] Y. Li, "Intelligent sensor technology in automotive electronic technology," IEEE, vol. 48, no. 10, pp. 56-60, 2019.

[8] Z. Sun, C. Li, L. Wei, Z Li, Z Min, and G Zhao, "Intelligent sensor-cloud in fog computer: a novel hierarchical data job scheduling strategy," Sensors (Basel, Switzerland), vol. 19, no. 23, pp. 23-25, 2019.

[9] Z. Cai, D. Li, and L. Deng, "Smart city framework based on intelligent sensor network and visual surveillance," Concurrency and Computation: Practice and Experience, vol. 26, no. 10, pp. 89-90, 2019.

[10] B. A. Akyol, J. N. Haack, and P. A. Craig, "Elligent sensor and controller framework for the power grid," Sensors, vol. 63, no. 897, pp. 458-490, 2019.

[11] Y. Xie, "Intelligent sensor detection technology in lighting design and application," Measurement, vol. 50, no. 150, pp. $45-48,2019$.

[12] F. Philipp, "Intelligent sensor technology: a 'must-have' for next-century," Marine Science, vol. 569, no. 10, pp. 48-60, 2019.

[13] D. Braun, "Intelligenter 14.0 Sensor für absolutes Linearfeedback," F \& M: Mechatronik, vol. 127, no. 5, pp. 30-32, 2019.

[14] A. Vangala, S. Pandey, and P. Parwekar, "Intelligent authentication model in a hierarchical wireless sensor network with multiple sinks," International Journal of Natural Computing Research, vol. 9, no. 48, pp. 369-370, 2020.

[15] D. Mwa, W. A. Xu, and B. Lty, "Multi sensor fusion based intelligent sensor relocation for health and safety monitoring in BSNs," Information Fusion, vol. 54, no. 40, pp. 61-71, 2020.

[16] A. Mukherjee, A. K. Panja, and N. Dey, "Intelligent sensor network," A Beginner's Guide to Data Agglomeration and Intelligent Sensing, vol. 36, no. 18, pp. 137-173, 2020.

[17] M. I. Raha, M. I. Hossain, and M. M. Farha, "A low cost intelligent multi wireless sensor network perspective on real time traffic surveillance international conference on computer, communication," Chemical, Materials and Electronic Engineering, vol. 489, no. 100, pp. 489-500, 2019.

[18] W. Yang, J. Huang, and P. Wang, "An intelligent distributed sensor developed for power cable external damage monitoring," Procedia Computer Science, vol. 183, no. 45, pp. 170-174, 2021.

[19] X. Xu, Y. Chen, and Z. Liu, "The value of intelligent ultrasound sensor used in the measurement of fetal hemodynamics and evaluation of health factors," Measurement, vol. 158, no. 11, pp. 107-110, 2020.

[20] F. Tan, "The algorithms of distributed learning and distributed estimation about intelligent wireless sensor network," Sensors (Basel, Switzerland), vol. 20, no. 5, pp. 130-132, 2020.

[21] W. Chen and X. Wang, "Coal mine safety intelligent monitoring based on wireless sensor network," IEEE Sensors Journal, vol. 46, no. 99, p. 1, 2020.

[22] Y. Li, Y. Cai, and I. R. Malek, "Creating navigation map in semi-open scenarios for intelligent vehicle localization using multi-sensor fusion," Expert Systems with Applications, vol. 184, no. 3, pp. 115-120, 2021.

[23] B. Alhayani and H. Llhan, "Visual sensor intelligent model Basics image transmission in industrial manufacturing for 
monitoring and manipulation problems," Journal of Intelligent Manufacturing, vol. 78, no. 1, pp. 336-340, 2020.

[24] A. Wrfel and D. Holly, "Multi sensor system intelligent berwachungder Ultras challreinigung," JOT, vol. 60 , no. 11 , pp. 42-43, 2020.

[25] R. Buettner, T. Rieg, and J. Frick, "Machine learning based diagnosis of diseases using the unfolded EEG spectra: towards an intelligent software sensor," Lecture Notes in Information Systems and Organization, vol. 789, no. 450, pp. 78-80, 2020.

[26] Z. Quan, H. He, and H. Zhou, "Designing an intelligent nanofiber ratiometric fluorescent sensor sensitive to biogenic amines for detecting the freshness of shrimp and pork," Sensors and Actuators B: Chemical, vol. 15, no. 489, pp. 129-135, 2021.

[27] J. ., A. Lei, A. Rc, and A. Jx, “A stick-like intelligent multicolor nano-sensor for the detection of tetracycline: the integration of nano-clay and carbon dots-Science Direct," Journal of Hazardous Materials, vol. 48, no. 100, pp. 489-490, 2021.

[28] N. Gao, Q. Ni, and D. Feng, "Physical layer authentication under intelligent spoofing in wireless sensor networks," Signal Processing, vol. 166, no. 10, pp. 107-272, 2020.

[29] S. Ricardo, B. Ricardo, and M. Mário, "The usage of an intelligent virtual sensor as a form of approximation to the final consumer," Advances in Intelligent Systems and Computing, Ambient Intelligence-Software and Applications-, 9th International Symposium on Ambient Intelligence, vol. 456, no. 48, pp. 489-490, 2019.

[30] M. Jing, K. Park, and M. Song, “An intelligent CMOS image sensor with a deep learning algorithm for smart IoT 2019 34th international technical conference on circuits/systems," Computer and Communications, vol. 45, no. 14, pp. 48-50, 2019.

[31] Y. ., U. Yang, Q. Chen, and H. Zhao, "Forest fire incidents monitoring based on wireless sensor network and intelligent optimization compressed sensing," Microcomputer Applications, vol. 456, no. 112, pp. 458-490, 2019.

[32] H. Tang, Z. ., L. Zhang, and B. ., F. Zhou, "Optimization on motion sequence of alignment platform between sensor intelligent chip and fiber array," Journal of Traffic and Transportation Engineering, vol. 569, no. 12, pp. 785-790, 2019.

[33] L. Latifah, D. Setiawan, and Y. A. Aryani, "Business strategy-MSMEs' performance relationship: innovation and accounting information system as mediators," Journal of Small Business and Enterprise Development, vol. 48, no. 485, pp. 45-50, 2020.

[34] M. ., L. Oktaroza and E. Halimatusadiah, "Accounting information system design for zakat on bandung Islamic University Baitul Maal," Proceedings of the 2nd Social and Humaniora Research Symposium (SoRes 2019), vol. 789, no. 256, pp. 486-490, 2020.

[35] D. Arif, N. Yucha, N. Yucha et al., "Applications of goods mutation control form in accounting information system: a case study in sumber indah perkasa manufacturing, Indonesia," The Journal of Asian Finance, Economics and Business, vol. 7, no. 8, pp. 419-424, 2020.

[36] W. Hui and F. Wei, "The impact of business environment and organizational culture on the implementation of management accounting information system in some hotels," Budapest International Research and Critics Institute (BIRCI-Journal): Humanities and Social Sciences, vol. 4, no. 3, pp. 6251-6262, 2020.

[37] B. A. Zhao and M. S. Qiu, "Accounting information system and financial sustainability of commercial and islamic banks: a review of the literature," Journal of Management Information and Decision Sciences, vol. 24, no. 5, pp. 1-17, 2020. 